\title{
A STUDY ON INCISIONAL HERNIA- CLINICAL PROFILE AND MANAGEMENT
}

\author{
Shajahan $Y^{1}$, Arun $S^{2}$ \\ ${ }^{1}$ Additional Professor, Department of General Surgery, Government T. D. Medical College, Alappuzha. \\ ${ }^{2}$ Senior Resident, Department of Neurosurgery, Government Medical College, Thiruvananthapuram.
}

\section{ABSTRACT}

\section{BACKGROUND}

Incisional hernia after abdominal surgery is a well-known complication and an important source of morbidity. It may be repaired either open/laparoscopically by anatomical or mesh repair. This study analyses the various aetiopathogenesis, mode of presentation, modalities of treatment and its outcome.

\section{MATERIALS AND METHODS}

Descriptive Study-The patients clinically diagnosed as incisional hernia were admitted to surgical wards in Govt. T. D. Medical College, Alappuzha, from $1^{\text {st }}$ January 2013 to $30^{\text {th }}$ June 2014 were subjected to anatomical or mesh repair depending upon the surgeon's choice and size of the hernia defect. Data was collected and analysed by various statistical methods.

\section{RESULTS}

Incisional hernia was found to be the second most common type of hernia. The incidence was more common in females, who underwent gynaecological procedures by lower and midline incisions. It was found to be more common in the age group of 30-50 years. Predominant risk factors being wound infection and obesity. Majority of patients presented with swelling and within 5 years of previous surgery. The postoperative complications noted were mainly wound infections and seroma complication. Mesh repair results in less recurrence than anatomical repair for incisional hernia.

\section{CONCLUSION}

It is not uncommon, an avoidable iatrogenic malady. Proper pre-operative preparations and efficient surgical techniques can prevent incisional hernia recurrence. Various methods of surgery adopted, among which Mesh repair is the best either open or lap method.

\section{KEYWORDS}

Incisional Hernia; Anatomical Repair; Mesh Repair; Hernia Defect; Complications; Recurrence.

HOW TO CITE THIS ARTICLE: Shajahan Y, Arun S. A study on incisional hernia- clinical profile and management. J. Evolution Med. Dent. Sci. 2017;6(38):3108-3113, D0I: 10.14260/Jemds/2017/670

\section{BACKGROUND}

Incisional hernia is generally iatrogenic in origin. It is a protrusion of abdominal viscera through the previous operation site or traumatic wound of the abdominal wall except hernia site. The incidence of incisional hernia has been high at least 10 percent, even with the recent advancement in surgery, anaesthesiology, antibiotics, suture materials, etc. The incidence of incisional hernias is next to inguinal hernia and may be higher than reported statistics, because of the asymptomatic nature of most of the incisional hernias. But quite sometimes this is one incidence where the remedy has turned out to be worse than malady, wherein a patient who undergoes surgery for a relatively minor surgical problem may end up with a strangulated hernia. Among the various abdominal incisions, lower abdominal incisions are associated with higher incidences of incisional hernia. Most of the gynaecological operations are done through lower abdominal incisions. The pressure in the lower abdomen is higher compared to upper abdomen.

Financial or Other, Competing Interest: None.

Submission 05-04-2017, Peer Review 30-04-2017,

Acceptance 06-05-2017, Published 11-05-2017.

Corresponding Author:

Dr. Shajahan $Y$,

Shamiyana, Chirakkadavom,

Kayamkulam-690502,

Kerala.

E-mail: dr.yshajahan@yahoo.com

DOI: $10.14260 /$ jemds $/ 2017 / 670$

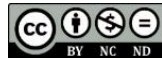

More than that the deficiency of the posterior rectus sheath below the umbilicus and the stress and strain on the lower abdomen predispose for herniations. There are number of aetiological factors for the development of incisional hernia, but the increased intra-abdominal pressure and the wound infections are the most important causes.

It should be noted by all surgeons who perform abdominal operations that occasionally the subsequent disability is worse than the reasons for original operation and their recurrence still worse. So while repairing incisional hernia the surgeon should use utmost care and select the method of repair and the suture material to prevent further recurrence. There are various methods of repair of abdominal incisional hernias, simple resuturing is used to repair small defect. Shoelace darn repair, ${ }^{1}$ Cattell's and Maingot's ${ }^{2}$ and Keel repair are in vogue. These anatomical repairs are associated with recurrence rate of 15 to 20 percent. In recent days, Polymer chemistry has revolutionised the suture material with nylon, polymer, polyester, polypropylene, polytetrafluoroethylene PTFE, polygalactyl and polydioxanone. Prosthetic grafts have revolutionised every surgical field. The modern era of prosthetic hernia repair began in 1958 with Usher reporting his experience with polypropylene prolene mesh. Since then polypropylene mesh has been widely used to cover wide defects in incisional hernia with excellent results. ${ }^{3}$ Despite so many advances in surgery, incisional hernia is not a rarity nor its management a problem. Most of the incisional hernia presented with large defects following post-operative wound infections. In 
patients who have undergone previous ${ }^{4}$ anatomical repair resulting in wider defect with scarring to prevent recurrence, prolene mesh had to be used. So it was felt worthwhile to study the results of repair using5,6 Prolene mesh and Anatomical repair in incisional hernia. The clinical study and management of incisional hernia of the abdominal wall was conducted at Govt. T. D. Medical College, Alappuzha, from 1st January 2013 to 30th June 2014.

\section{Aims and Objectives}

The purpose of this dissertation is to study various risk factors and management of incisional hernias at Department of Surgery, Govt. T. D. Medical College, Alappuzha. The study period is from 1st January 2013 to 30th June 2014.

1. Analysis of various aetiological factors leading to incisional hernia.

2. Analysis of case distribution in relation to age and sex.

3. Analysis of previous surgeries undergone.

4. Analysis of various surgical modalities in the treatment of incisional hernia like anatomical repair or mesh repair.

\section{MATERIALS AND METHODS \\ Study Design}

Descriptive Study.

\section{Setting}

The patients clinically diagnosed as incisional hernia admitted to surgical wards in Government T. D. Medical College, Alappuzha, from $1^{\text {st }}$ January 2013 to $30^{\text {th }}$ June 2014.

\section{Period of Study}

18 months.

\section{Case Definition}

The patients clinically diagnosed as incisional hernia were admitted to surgical wards in Government T. D. Medical College, Alappuzha.

\section{Inclusion Criteria}

The patients clinically diagnosed as incisional hernia were admitted to surgical wards in Government T. D. Medical College, Alappuzha.

\section{Exclusion Criteria}

1. Other hernias of anterior abdominal wall.

2. Patients who are unfit for anaesthesia.

3. Complicated hernia (Recurrent).

4. Incisional Hernia during gestation.

5. All patients below the age of 12 years.

\section{Sample Size}

The patients clinically diagnosed as incisional hernia were admitted to surgical wards in Government T. D. Medical College, Alappuzha, from $1^{\text {st }}$ January 2013 to $30^{\text {th }}$ June 2014; final sample size is 50 .

\section{Methodology}

The material composed of detailed study of 50 cases of incisional hernia admitted and treated in Department of Surgery, T. D. Medical College, Alappuzha, from 1st January 2013 to 30th June 2014. In this series, the patients who were admitted in general surgical wards were examined to assess the tissue defects, aetiological causes, precipitating factor, etc. Any associated conditions were identified and treated preoperatively. A detailed history was taken, clinical examination and necessary investigations were carried out according to proforma. After detailed physical examination of patients, clinical diagnosis was established including the associated aetiological, precipitating and predisposing factors. Finally, decision was made for every case regarding the method of repair. Fifty cases underwent operation. Preoperative optimisation of the patients was done. All cases were analysed to find out the pros and cons of various operative techniques, need of good postoperative care and the results of surgery.

\section{Statistical Analysis}

Qualitative variables were summarised using percentages and proportions. All analysis was done using SPSS software.

\section{Ethical Considerations}

Study was conducted only after getting approval from Institutional Ethical Committee. A written informed consent was taken from all the patients included in the study.

\section{RESULTS}

Observation and Analysis

During the period of our study from January 2013 to June 2014 around 687 operations were carried out for various types of abdominal hernias.

\begin{tabular}{|c|c|c|}
\hline Type of Hernia & $\begin{array}{c}\text { Number of } \\
\text { Cases }\end{array}$ & Percentage \\
\hline Inguinal & 536 & 78.02 \\
\hline Incisional & 50 & 7.28 \\
\hline Femoral & 18 & 2.62 \\
\hline $\begin{array}{c}\text { Umbilical and } \\
\text { Paraumbilical }\end{array}$ & 41 & 5.97 \\
\hline Epigastric & 42 & 6.11 \\
\hline Spigelian & 0 & 0 \\
\hline Obturator & 0 & 0 \\
\hline Lumbar & 0 & 0 \\
\hline Total & 687 & 100 \\
\hline \multicolumn{2}{|c|}{ Table 1. Incidence of Incisional Hernia } \\
\hline
\end{tabular}

Inguinal hernia was the most common type accounting for $78.02 \%$, next common hernia was incisional hernia (7.28\%), remaining rare types constituting $14.7 \%$ of total cases studied.

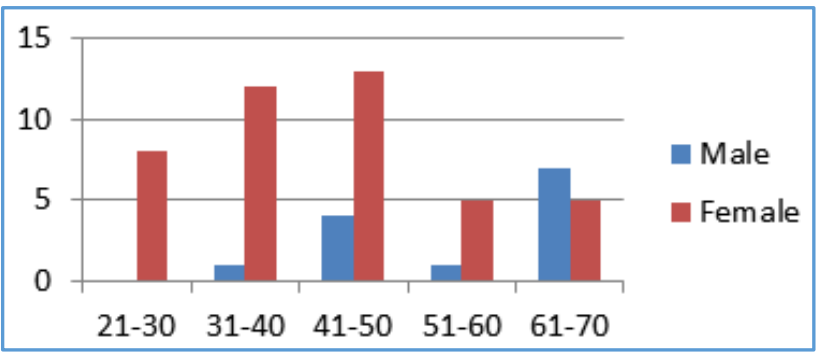

Figure 1. Age Wise Incidence of Incisional Hernia

It shows that maximum number of cases were in middle age group of 20 to 50 (i.e. 38 out of 50 cases). Youngest case21 years Eldest Case of 70 years. 


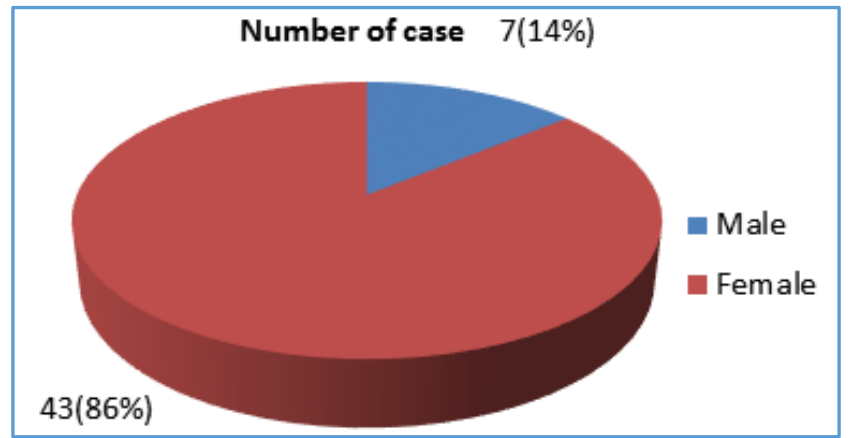

Figure 2. Male-to-Female Ratio

Out of 50 cases, 43 were females and 7 were males.

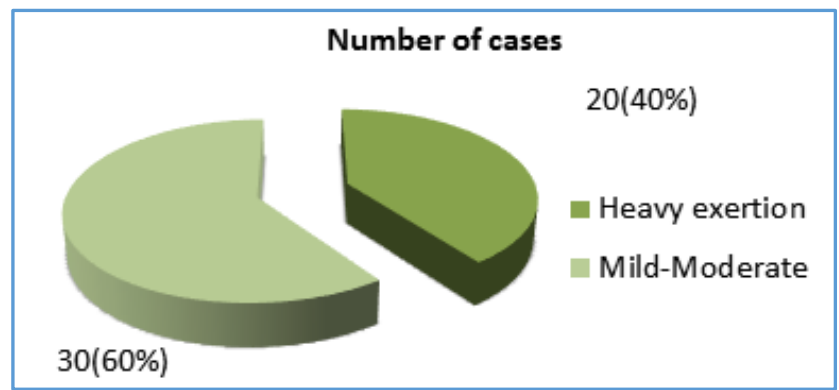

Figure 3. Occupation of the Patients

Forty percent of patients in this series are manual workers or labourers. It is generally believed that severe straining and heavy lifting are more frequently associated with development of incisional hernia due to increased intraabdominal pressure.

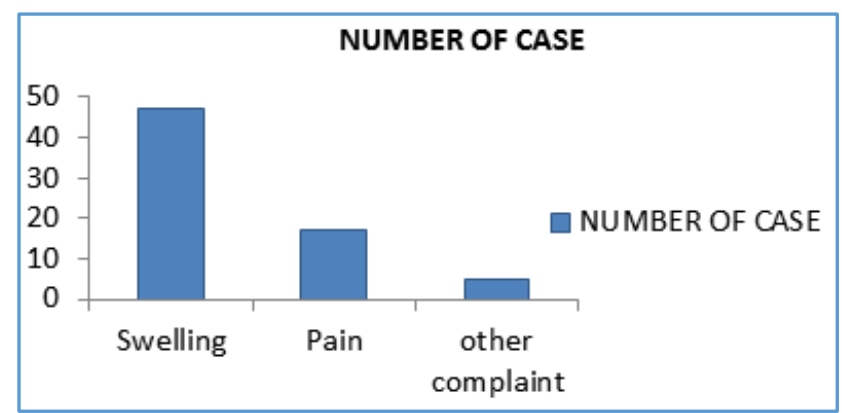

Figure 4. The Distribution of Case according to Symptom

The commonest symptom was swelling (87\%) and pain (37\%). Swelling was visible on standing or exertion. The pain was intermittent, colicky and was suggestive of adhesion.

\begin{tabular}{|c|c|c|}
\hline Risk Factor & No. of Case & Percentage \\
\hline Obesity & 18 & 36 \\
\hline Multiparity & 22 & 44 \\
\hline Anaemia & 18 & 36 \\
\hline Diabetes & 6 & 12 \\
\hline Asthma & 5 & 10 \\
\hline Chronic Bronchitis & 2 & 4 \\
\hline Hypertension & 7 & 14 \\
\hline \multicolumn{2}{|c|}{ Table 2. The Distribution of Risk Factor } \\
\hline
\end{tabular}

Multiparity, obesity and anaemia were the most common predisposing factors described by (Christoper and Sabiston). Chronic bronchitis, asthma, diabetes and other were less common factors.

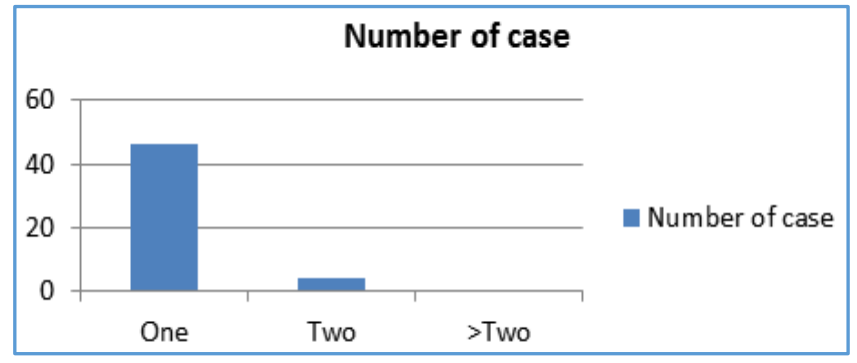

Figure 5. Number of Previous Abdominal Surgery

Out of 50 patients, 46 had a single operation only and 4 had two operations.

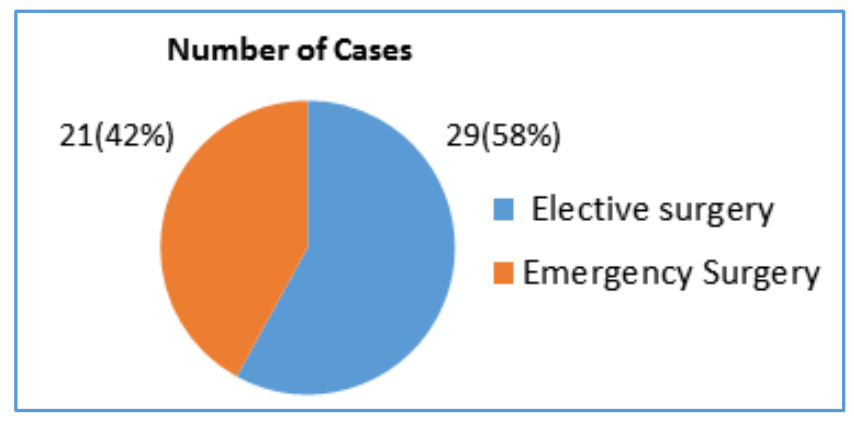

Figure 6. The Nature of Previous Surgery

Majority underwent elective operation.

\begin{tabular}{|c|c|c|}
\hline Operation Type & No. of Cases & Percentage \\
\hline Abdominal Hysterectomy & 13 & 26 \\
\hline Abdominal Sterilisation & 15 & 30 \\
\hline Lower Segment Caesarean Section & 14 & 28 \\
\hline Acute Intussusception-Laparotomy & 1 & 2 \\
\hline Duodenal Perforation-Laparotomy & 4 & 8 \\
\hline $\begin{array}{l}\text { Appendicular Perforation- } \\
\text { Laparotomy }\end{array}$ & 2 & 4 \\
\hline Epigastric Hernia-Laparotomy & 1 & 2 \\
\hline Total & 50 & 100 \\
\hline
\end{tabular}

Gynaecological conditions were the major cause for surgeries $(84 \%)$.

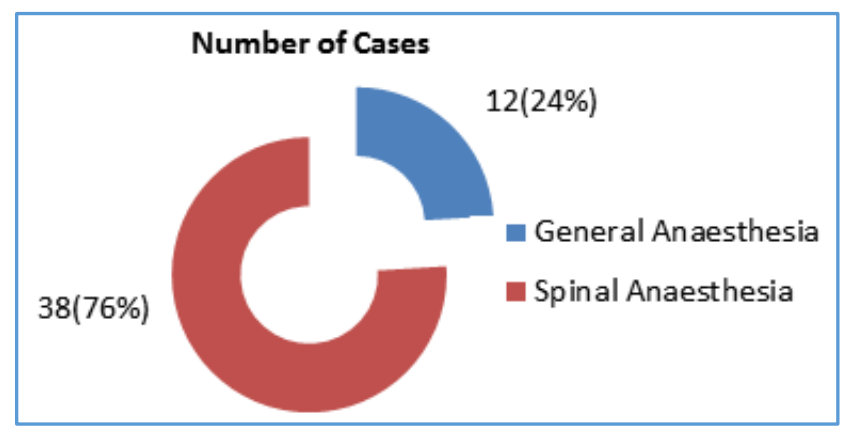

Figure 7. Type of Anaesthesia for Previous Surgery 
Majority were operated under Spinal Anaesthesia.

\begin{tabular}{|c|c|c|}
\hline Type of Incision & Number of Cases & Percentage \\
\hline Infraumbilical (Midline) & 40 & 80 \\
\hline Supraumbilical (Midline) & 6 & 12 \\
\hline Right Paramedian & 2 & 4 \\
\hline Pfannestiel's & 2 & 4 \\
\hline Total & 50 & 100 \\
\hline
\end{tabular}

There was preponderance of infraumbilical midline incision (80\%) in the present study.

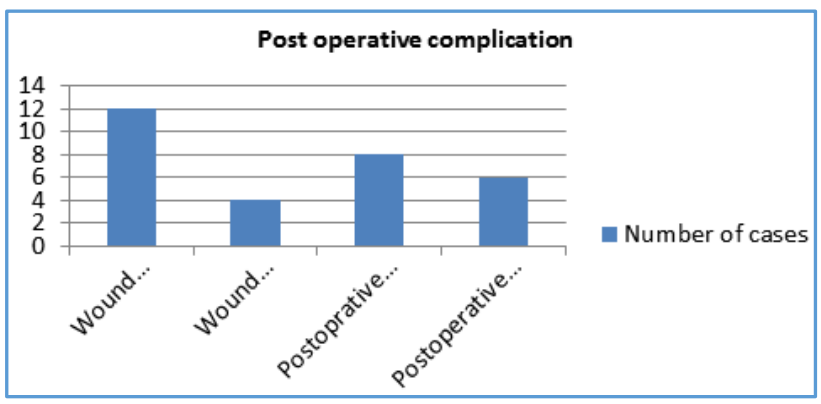

Figure 8. Postoperative Complication in Previous Surgery

There was high incidence of post-operative complications after operative procedures. Wound infection was the main complication noted. Wound disruption, post-operative cough were the other post-operative complications that were noted.

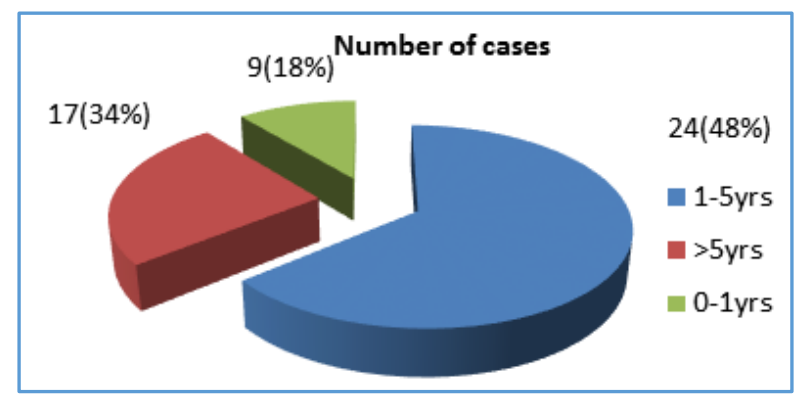

Figure 9. Time of Appearance of Hernia after Previous Surgery

In our series, $18 \%$ of cases appeared within 1 year. Majority occurred within 5 years.

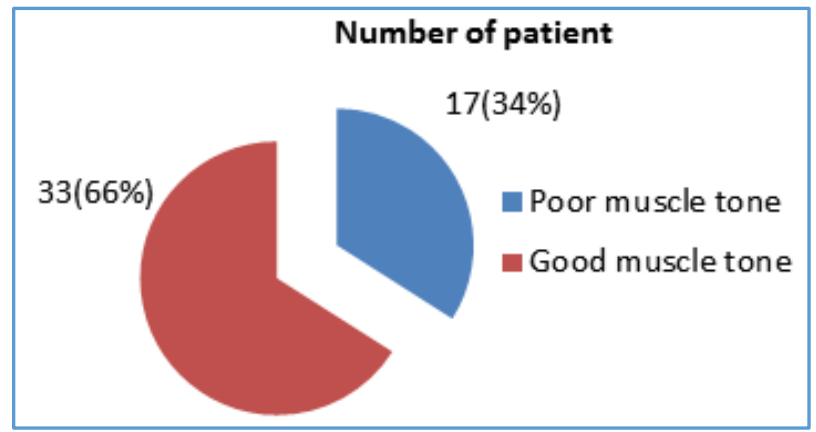

Figure 10. Abdominal Muscle Tone
Thirty-four percent had poor abdominal tone, (Grading was done clinically. Patient with Malgaigne's bulge were considered as patients with poor muscle tone).

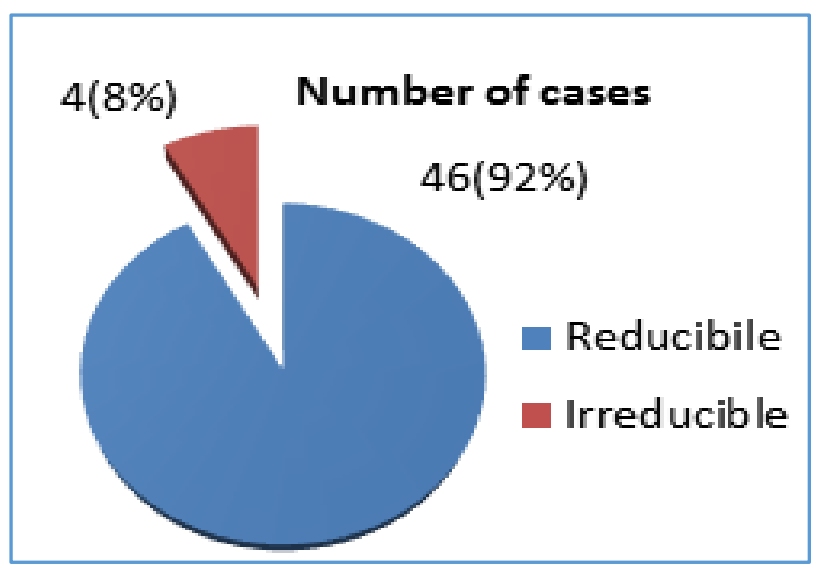

Figure 11. Reducibility of Hernia

Most hernias were reducible spontaneously on lying down.

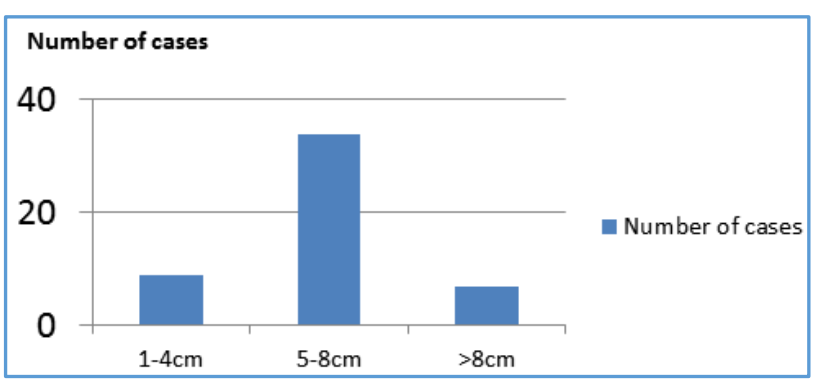

Figure 12. The Size of Defect of Hernia

Many cases had the defect of 5 - $8 \mathrm{cms}$

\begin{tabular}{|c|c|c|}
\hline $\begin{array}{c}\text { Operative } \\
\text { Procedure }\end{array}$ & $\begin{array}{c}\text { Number of } \\
\text { Cases }\end{array}$ & Percentage \\
\hline Resuture & 0 & 0 \\
Maingot's Keel & 3 & 6 \\
operation & 2 & 4 \\
Shoelace repair & 0 & 0 \\
Mayo's repair & 0 & 0 \\
Onlay Mesh repair & 45 & 90 \\
Preperitoneal mesh & & 100 \\
repair & 50 & \multicolumn{2}{|c|}{} \\
\hline Total & \multicolumn{2}{|c|}{ Table 5. Operative Procedure Done } \\
\hline \multicolumn{2}{|c}{}
\end{tabular}

Only 4 cases were repaired by anatomical repair. Most of the cases have repaired by onlay mesh repair.

\begin{tabular}{|c|c|c|}
\hline $\begin{array}{l}\text { Post-Operative } \\
\text { Complication }\end{array}$ & No. of Cases & Percentage \\
\hline Uneventful & 5 & 100 \\
\hline Wound infection & 0 & 0 \\
\hline Seroma & 0 & 0 \\
\hline Postoperative Cough & 0 & 0 \\
\hline Distension of Abdomen & 0 & 0 \\
\hline Total & 5 & 100 \\
\hline \multicolumn{3}{|c|}{$\begin{array}{c}\text { Table 6. Post-Operative Complication } \\
\text { following Anatomical Repair }\end{array}$} \\
\hline
\end{tabular}




\begin{tabular}{|c|c|c|}
\hline $\begin{array}{l}\text { Post-Operative } \\
\text { Complication }\end{array}$ & No. of Cases & Percentage \\
\hline Uneventful & 37 & 82.22 \\
\hline Wound Infection & 3 & 6.67 \\
\hline Seroma & 4 & 8.89 \\
\hline Postoperative Cough & 0 & 0 \\
\hline Distension of Abdomen & 1 & 2.22 \\
\hline Total & 45 & 100 \\
\hline
\end{tabular}

Patients out of 50, 8 had complications, wound infection, distension of abdomen and seromas were more in prolene mesh repair. Prolene being foreign material induces little more tissue reaction.

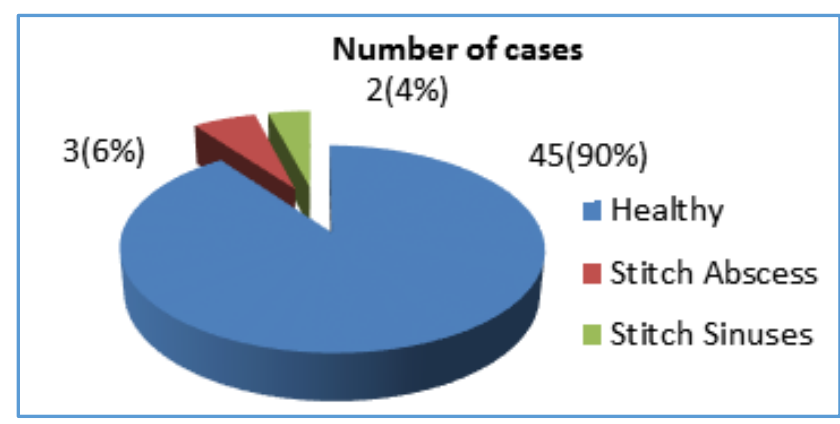

Figure 13. Followup at End of One Month

The condition of scar after $1^{\text {st }}$ and $6^{\text {th }}$ month was recorded, Stitch Abscess-Drained under local anaesthesia. Stitch Sinuses-Stitch removed after exploration under local anaesthesia and sinus healed.

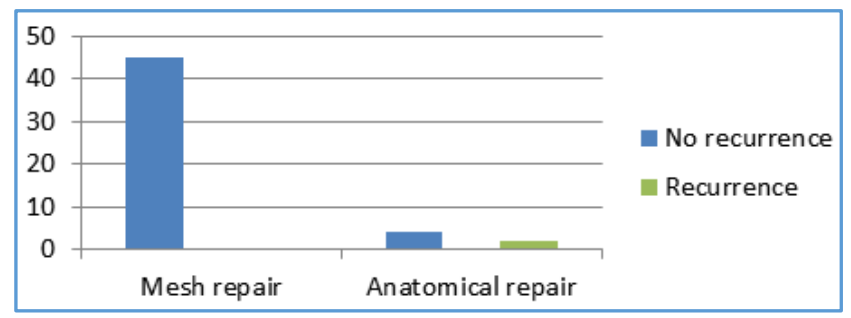

Figure 14. Recurrence up to 30/June/2014

Even though Usher invented prolene mesh, in his own two series gives recurrence rates of $10.8 \%$ in 1958 and 'Zero' in 1970. In our series, there was no recurrence with prolene mesh repair. One case developed recurrence with anatomical repair with an incidence of $2 \%$.

\section{DISCUSSION}

Out of 687 cases of hernias admitted to Govt. T. D. Medical College, Alappuzha, from 1st January 2013 to 30th of June 2014, incisional hernias constituted 7.28 percent. Most of the patients were asymptomatic except for the protrusion and mild abdominal discomfort. Maximum age incidence was between 20-50 years. Incisional hernia was found to be more common in females. While studying the predisposing factors for the development of incisional hernia, it was found that multiparity, obesity, wound infection, post-operative cough and diabetes were the most important predisposing factors.
In our study, most incisional hernias occurred following elective operations and most of them were gynaecological operations. In $18 \%$ of the cases, incisional hernias developed in the first year after previous surgery. About $48 \%$ developed during 2nd to 5 th postoperative year and about 34\% developed after 5 years. The incisional hernias were found in lower abdominal incisions in nearly $80 \%$ of the cases. There were 1 case who had recurrence with previous anatomical repair and they had wider defects. They were chosen for prolene mesh repair. Out of 50 patients admitted for incisional hernia repair, 45 cases were selected for prolene mesh repair. The criteria for selection being wider defects, predisposing factors and recurrence after anatomical repair. Rest of the cases underwent anatomical repairs like Keel operation and shoelace darning. Pre-operatively, the obese patients were asked to reduce their weight. The abdominal exercises were advised to increase the tone of the abdominal muscles.

Diabetics were controlled with Insulin. Hypertension was controlled. Chest infections were treated. Nutritional status and anaemia were corrected. All the investigations were done. The cases were put preperitoneal prolene mesh. The abdomen was closed with suction drains. Foley's catheter was put to decompress the bladder throughout the operation and was removed on the second day. Nasogastric aspiration was done for 24 hours. Broad spectrum antibiotics were used. The drains were removed on the 2nd or 3rd day. Sutures were removed on the 10th day. Wound infections when they occurred were treated by drainage and suitable antibiotics. Seromas were drained. In no case, there was rejection of mesh. The final wound healing was good. Compared to anatomical repair wound infection rate was more in mesh repairs, but the infections were controlled. There was no rejection of mesh or recurrence. The patients were discharged with the advice not to do any strenuous work. Despite problems, the patients were followed up for a period of 6 months to $1 \frac{1}{2}$ years. The followup period being very short, it is difficult to comment about recurrences. However, there was no recurrence with prolene mesh repair during the brief followup period.

\section{CONCLUSION}

1. An avoidable iatrogenic malady, but the incidence is not uncommon.

2. Though minimum mortality, the morbidity is sufficiently enough to incapacitate the patient to some extent.

3. Proper preoperative management of the patients, meticulous surgical technique and post-operative care go a long way in preventing the occurrence of incisional hernia.

4. Surgery is the only option and that should not be delayed and the same should be carried out at the earliest.

5. Maximum scarring prolene mesh repair is best for larger defects.

6. For recurrent incisional hernia, prolene offers excellent results and offers long life protection.

7. Though it is very costly, it is superior to any available repair.

8. Among patients with midline abdominal incisional hernias, mesh repair is superior to suture repair with 
regards to the recurrence of hernia, regardless of the size of the hernia.

\section{Summary}

Out of all hernias incisional hernia constituted $7.28 \%$ percent, next only to inguinal hernia. The incisional hernia, maximum age incidence being 40 to 50 years. All patients presented with protrusions. Few had pain and abdominal discomfort Two patients had vomiting. Majority of the patients were asymptomatic, except for the unsightly bulge. Incisional hernia was found to be more common in females. The incisional hernia occurred $18 \%$ in the first post-operative year. About $48 \%$ occurred in 2 nd to 5 th post-operative year. Thirty-four percent of cases developed incisional hernia after 5 years. Multiparity, obesity and post-operative wound infections were predominant predisposing factors. Postoperative cough, abdominal distension, diabetes and hypertension also contributed for development of hernia. In our small series, the incisional hernia had developed following elective surgeries in 58\% and $80 \%$ cases occurred in lower midline incisions. Majority of the patients who developed incisional hernias had undergone gynaecological operations. Even though the wound infection is more in mesh repairs than anatomical repairs, in no case there was rejection of mesh. In a short followup, it is difficult to comment about recurrence. However, there was no recurrence.

There was no mortality. One case of recurrence with anatomical repair were treated using prolene mesh with excellent result.

\section{REFERENCES}

[1] Abrahams J, Elder S. Shoelace repair of large postoperative ventral abdominal hernias: a simple extra peritoneal teach. ContempSurg 1988;32:24.

[2] Maingot R. A further report on the keel operation for large diffuse incisional hernias. Med Press 1958;240:989.

[3] Usher FC. Hernia repair with knitted polypropylene mesh. SurgGynecalObeset1963;117:239-40.

[4] Throckmorton TD. Tantalum gauze in the repair of hernias complicated by tissue deficiency. Surgery 1948;23:32.

[5] McArthur LL. Autoplastic suture in hernia and other diastases: preliminary report. JAMA 1901;37(18):1162-5.

[6] Mair GB. Preliminary report on the use of whole skin grafts as a substitute for fascial sutures in the treatment of hernias. Br J Surg 1945;32(127):381-5. 